\title{
Praxistipp
}

\section{Volumen von Operationspräparaten einfach bestimmen}

\author{
Wie ermittelt man Größe oder Volumen von Operationspräparaten der \\ Haut entsprechend den Vorgaben des Kapitels 31 des EBM? Mit \\ Messungen vor, während oder nach dem Eingriff stößt man schnell an \\ die Grenzen der jeweiligen Methode. Dabei gibt es ein Hilfsmittel, mit \\ dem man in kurzer Zeit weiß, ob das Exzidat die erforderliche Größe \\ hat.
}

m Kapitel 31 des Einheitlichen Bewertungsmaßstabs (EBM) werden Parameter zur Definition der Größe eines operativ entfernten Tumors aufgeführt (Fläche $4 \mathrm{~cm}^{2}$, Länge $3 \mathrm{~cm}$, Volumen $1 \mathrm{~cm}^{3}$ ), die sich nicht immer leicht bestimmen lassen. Präoperative Messungen auf der Haut werden oft durch geändertes chirurgisches Vorgehen aufgehoben. Messungen am blutigen und geometrisch unregelmäßigen Operationspräparat sind ebenfalls problematisch und zeitraubend. Messungen am fixierten Material im histologischen Labor sind wegen Schrumpfungs- und Fixierartefakten nicht repräsentativ für den intraoperativen Zustand.

\section{Unkompliziertes Wiegen statt umständlichem Messen}

Die Lösung bringt ein einfaches, schnelleres und viel genaueres Verfahren: Das Material wird gewogen. Da Körperge-

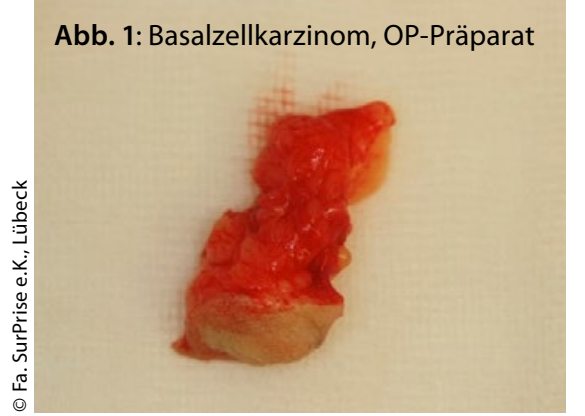

webe eine Dichte von etwas weniger als $1 \mathrm{~g} / \mathrm{cm}^{3}$ hat, entspricht eine Masse von wenig mehr als $1 \mathrm{~g}$ recht genau dem im EBM geforderten Volumen von $1 \mathrm{~cm}^{3}$. Lediglich bei einem höheren Anteil von Fettgewebe sollte eine kleine Korrektur erfolgen.

Als Waage bietet sich eine elektronische Briefwaage an. Zunächst stellt man das mit Fixierlösung beschickte Versandgefäß auf die Waage und setzt die Wägung durch Betätigen des TaraKnopfes auf Null (Abb. 2). Anschließend wird das exzidierte Material (Abb. 1) in das Versandgefäß gelegt und das Ge-

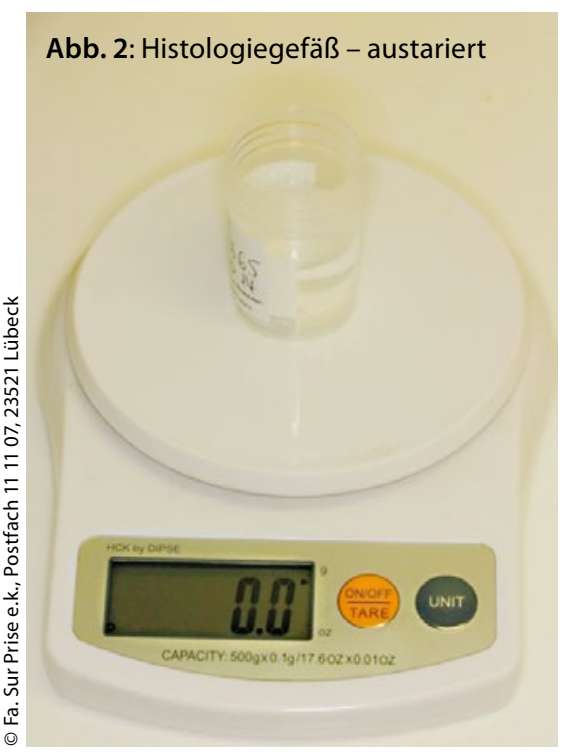

wicht ist sofort ablesbar (Abb. 3). Jedes Gewebsstück von mehr als circa 1,1 g erfüllt die Forderung des EBM-Kapitels 31 "groß“ zu sein. Reines Fettgewebe würde ab einer Masse von circa 1,25 g ebenfalls dieser Bestimmung genügen. Alle Messungen von Länge oder Volumen entfallen damit.

Um die EBM-Vorgaben zu erfüllen, vermerkt man im Operationsprotokoll sicherheitshalber folgenden Text: „xxx g Gewebe entsprechen bei einer Dichte von circa $1 \mathrm{~g} / \mathrm{cm}^{3}$ einem Volumen von yyy $\mathrm{cm}^{3}$ ). Damit sind die Vorgaben des EBM auch formal erfüllt.

Das geschilderte Vorgehen wurde mit Dr. med. Dipl. Biol. Matthias Kießling (Sonderrefent für Operative Dermatologie des Berufsverbands der Deutschen Dermatologen) abgestimmt.

PD Dr. Dr. med. Jürgen F. Kreusch Moislinger Allee 95

23558 Lübeck

E-Mail: j.kreusch@derma.de

Abb. 3: Wägung des Histologiegefäßes mit dem Exzidat: 1,1 g

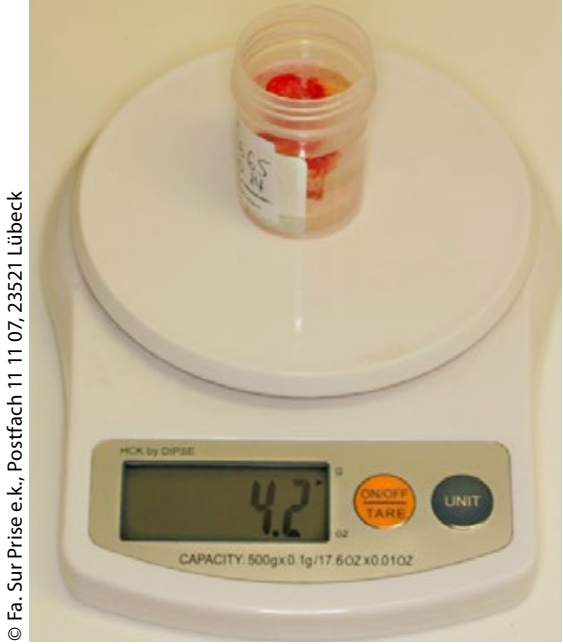

